\title{
Aspectos da pintura política na França: de Civilização atlântica ao Ateliê Popular (1953-68)
}

Leandro Cândido de Souza ${ }^{1}$

\section{Resumo:}

Este artigo tem como objetivo analisar a pintura política francesa entre os anos de 1953 e 1968: da primeira apresentação da obra Civilização atlântica, de André Fougeron, à criação do Ateliê Popular, durante a ocupação da Escola de Belas Artes de Paris, no Maio de 1968. Primeiramente, abordaremos os movimentos artísticos surgidos no período - Figuração Crítica, Figuração Narrativa, Salão da J ovem Pintura etc. - como inauguradores de uma nova etapa do processo de politização da arte naquele país. Num segundo momento, destacaremos algumas características dessa nova pintura - como a anulação da autoria individual, a coletivização do processo criador e a lide com o compartilhamento técnico delas decorrente - , enfatizando as relações que elas estabelecem com um contexto histórico de financeirização transnacional da arte, capitaneada pelos Estados Unidos.

Palavras-chave: pintura política; arte contemporânea; Salão da J ovem Pintura; instituição artística; Maio de 68.

\section{Aspects of political painting in France: From Atlantic Civilization to the Atelier Populaire (1953-1968)}

\begin{abstract}
:
The objective of this article is to analyze the French political painting between 1953 and 1968: from the first presentation of the work Atlantic Civilization, by André Fougeron, to the creation of the Atelier Populaire during the occupation of the École des Beaux-Arts in Paris in May 1968. First, we discuss the artistic movements that arose during that period critical figuration, narrative figuration, Salon of Young Painting etc. - as inaugurating a new stage in the process of politicizing art in that country. Next, we highlight some characteristics of this new painting - such as the annulment of individual authorship, the collectivization of the creative process, and the technical sharing that resulted from them - emphasizing
\end{abstract}

\footnotetext{
${ }^{1}$ Doutor em história pela Pontifícia Universidade Católica de São Paulo (PUC-SP), pósdoutor pela Universidade Estadual Paulista (FCL/Unesp - Assis), com estágios na Universidad de Buenos Aires (FFyL/UBA) e na École des Hautes Études en Sciences Sociales. E-mail: lecanza@yahoo.com.
} 
the relations established with the historical context of the transnational financialization of art spearheaded by the USA.

Key words: political painting; contemporary art; Salon of Young Painting; artistic institutions; May 1968.

\section{Paris, Nova York e o fim da arte moderna}

O Maio parisiense de 1968 ficou marcado, ao menos para a história da arte, como o momento deflagrador de novos agrupamentos artísticos, associações, movimentos e exposições coletivas que tentavam dar continuidade ao processo de politização da arte francesa iniciado no século anterior. No centro de suas ações, coexistiam questões relativas ao status da obra de arte na contemporaneidade, ao papel social do artista no segundo pós-guerra e à centralização oligopolista das instituições artísticas. Ainda que essa politização da arte não fosse inédita, ela registrava bem as diferenças entre a modernidade, cujo projeto final foi apresentado pelos grupos "modernistas" da segunda metade do século XIX, e a pós-modernidade, iniciada com as neovanguardas dos anos 195060 e consolidada pelo conceito de "arte contemporânea".

No campo das artes plásticas, esse processo foi minuciosamente analisado por Serge Guilbaut (1996), e suas consequências estéticas - bem como as inevitáveis implicações epistemológicas dessa transição - foram sintetizadas por Hal Foster (1985), ainda que variando o registro. Se retrocedermos a cronologia para tratarmos diretamente das fontes que registram essa transformação por que passou a história da arte - tanto o sistema artístico internacional como a historiografia que o aborda - , localizaremos o início desse itinerário no debate sobre o sentido assumido pelo desenvolvimento do mercado de arte nos Estados Unidos, notadamente em torno da preparação de uma arte internacionalista e pretensamente apolítica (GUILBAUT, 1996, pp. 27-63).

Na Paris dos anos 1950, pela primeira vez a pintura foi concebida como espaço de resposta a essa política de monopolização do mercado de arte, que desde então passou a ser encarado como um agente impessoal autoritário que utiliza a censura e o dogmatismo estético como principais ferramentas de trabalho. Esse foi o modo como chegou à França o conjunto institucional hoje denominado "pós-moderno". Mais especificamente por meio de auxílios e financiamentos (bolsas de estudo, compra de obras, construção de museus etc.) que, junto ao Plano Marshall e agências de estado, como a Central Intelligence Agency (CIA), incluíam a importação consciente dos padrões da arte estadunidense recémproduzida. Como assinalou Perry Anderson, essa profunda renovação no 
debate artístico indicava como, depois da guerra, "Paris tinha perdido indiscutivelmente o lugar de capital da pintura moderna que ela detinha há um século" (ANDERSON, 2005, p. 22). Ou, de modo mais amplo, Paris perdeu sua posição dominante sobre o mercado cultural internacional e, ao mesmo tempo, seu prestígio invejado de polo da modernidade.

Para comprovar essa condição de "um país [França] que descobre que sua influência política é secundária e que sua influência cultural não é mais universal" (PERROT, 2002, p. 63), basta constatarmos a sucessão de movimentos artísticos vindos, desde então, dos Estados Unidos, como o expressionismo abstrato, a Pop Art e o que lhe seguiu: Optic Art, minimalismo, conceitualismo, Land Art etc. Expressão mais que eloquente dessa nova dominante cultural, a Pop Art se consagrou em 1964, com o prêmio concedido a Robert Rauschenberg na Bienal de Veneza, depois de seus quadros terem sido transportados até o evento pela Força Aérea estadunidense. Tudo indicava se tratar mais de uma política de estado que de uma tendência estilística: entravam em cena grandes agências transnacionais de difusão cultural com a indisfarçável finalidade de dominação ideológica.

A resposta oficial francesa viria pelas mãos de André Malraux, durante o governo De Gaulle (1959-69). Malraux havia feito parte da resistência contra os nazistas ao lado de De Gaulle, que o encarregou de preparar o terreno para a centralização cultural que seria terminada pela política de Georges Pompidou (1969-74). Dez anos foram necessários a Malraux para lançar as bases da "arte contemporânea” na França, a partir de uma política aparentemente descentralizadora que dividia para reorganizar. As Maisons de la Culture foram seu principal veículo, verdadeiras "ferramentas de seleção e dominação" que impuseram o abandono das orientações "populares" e institucionalizaram uma "nova elite de tecnocratas culturais" (DERIVERY, 2001a, p. 50). A partir de então, especialmente desde 1968, as Maisons de la Culture se tornaram um percurso obrigatório para os artistas excluídos dos espaços comerciais ${ }^{2}$.

A centralização que sucedeu a essa descentralização coordenada só foi completada por Pompidou e sua "política da cenoura e do bastão", oficializada com a Exposição 72-72 (DERIVERY, 2001b). Dando migalhas a poucos e reprimindo muitos, Pompidou pôs em marcha uma autêntica "guerra de usura" contra todo tipo de agrupamento coletivo, num conflito declarado que chegou a seu ponto máximo na Assembleia de Créteil (3 de janeiro de 1977), com mais de mil artistas organizados contra o dirigismo

2 A primeira Maison de la Culture foi criada em Paris, na rua Navarin, na primavera de 1935, unificando associações favoráveis ao Front Populaire (cf. PERROT, 1996, p. 152; NICOLE, 2003). Para uma melhor compreensão das transformações do mercado de arte na França a partir da década de 1960, consultem-se os trabalhos de François Derivery (2001a; 2004). 
autoritário representado pela construção do Centro Cultural Georges Pompidou (1969-78).

É esse contexto que devemos ter em mente quando analisamos o surgimento de grupos artísticos como os envolvidos na Figuração Crítica, na Figuração Narrativa, no Salão da J ovem Pintura e no Ateliê Popular, principalmente quando tentamos mensurar suas consequências quanto ao status da obra de arte na sociedade burguesa, assumindo um papel marcadamente político ao tentar reativar o realismo frente a um mercado rígida e sistematicamente controlado. A autonomia estética, que só é possível quando o artista se encontra relativamente independente das pressões da religião, da política, do mecenas ou das demais esferas da práxis vital (encomenda), foi anulada na segunda metade do século XX por meio de um rigoroso sistema de valoração artística, segundo o qual é necessária uma constante autocensura para a viabilização das obras 3 .

Abrir espaço para a reconstituição do período de retomada da figuração na França nos leva, portanto, de volta aos eventos franceses do Maio de 1968, seus antecedentes e implicações, sobretudo no que diz respeito à nova onda internacional dos agrupamentos artísticos. Durante os anos 1960, muitos grupos já se propunham a "dessacralizar a arte, a figura do artista, interrogar sua capacidade de criar coletivamente e inventar propostas artísticas investidas de um aporte político e social". Entre eles, estavam o Groupe de Recherche d'Art Visuel (Grav, 1961-8), o grupo Panique (1966-), Equipo Crónica (1965-81), BMPT (Daniel Buren, Olivier Mosset, Michel Parmentier e Niele Toroni, 1966-7), Supports/Surfaces (1969-74), além da Coopérative de Malassis, em fermentação desde 1968, e dos artistas envolvidos no novo realismo, na Figuração Crítica e Narrativa (CHAMBARLHAC; LAVIN; TILLIER, 2014, pp. 49-51).

O ativismo dos agitadores Dada na Europa, que deve ser
diretamente associado à Grande Carnificina de 1914-18, a se
interpretar como um sintoma dessas transformacões radicais
em gestação, no contexto de uma erosão irremediável da "Arte".
Do mesmo modo, no início dos anos 1960, os Fluxus, BMPT,
Supports/ Surfaces, por exemplo, foram sintomas no mesmo
sentido. A vontade de uma superação da arte - de certo modo
abordado - pelos Situacionistas (...). É o que o Manifesto da
Internacional Situacionista de 17 de maio de 1960 afirmava:

3 Michel Dupré define com precisão o sistema de valoração de obras, ainda que sem recorrer a essa terminologia: "A produção se faz por fora de todo gasto do patrocinador (real ou virtual) que será (ou não) o comprador potencial do produto (obra) por um preço que, na realidade, ele mesmo fixa. O produto (obra) se tornará objeto de especulação por intermédio da infraestrutura comercial e midiática (galerias, editoras, museus...) da qual a burguesia financeira é proprietária. Uma forma de mercado que se parece com as práticas econômicas do colonialismo, e deve ser, do mesmo modo, denunciada." (DUPRÉ, 2015, p. 131). Todas as traduções de textos em língua estrangeira são de responsabilidade do autor. 
"todo mundo se tornará artista, em um sentido que os artistas não alcançaram". (DUPRÉ, 2015, pp. 53-119)

Debord, os letristas internacionalistas e os situacionistas foram certamente herdeiros do surrealismo, mas se afastaram deste na medida em que se conciliavam com o materialismo e o racionalismo franceses do período das Luzes4. Talvez esse seja o mediador mais adequado entre o Maio de 68 e as vanguardas históricas, em especial o movimento liderado por Breton, como, aliás, notou Peter Bürger ao salientar a conexão existente entre a cultura contemporânea e a questão inaugural das vanguardas de princípio do século $\mathrm{XX}$, finalizando o ciclo da arte autônoma, quer dizer, proclamando a morte da arte burguesa modernista. A análise de Bürger, como a dos demais autores mencionados neste trabalho, não nega as diferenças notáveis que existem entre as aspirações das vanguardas históricas das três primeiras décadas do século XX e os movimentos artísticos do segundo pós-guerra, os quais o autor denomina "neovanguardas". No entanto, essas diferenças não o impediram de reconhecer linhas de continuidade entre os dois momentos ou, ao menos, entre algumas dessas propostas de refuncionalização política da arte após a anulação da autonomia estética burguesa (BÜRGER, 2001) ${ }^{5}$.

Michael Löwy dá alguns passos adiante em sua interpretação desse mesmo momento histórico, destacando que, para além da tentativa de superar a distância entre arte e vida, há uma segunda "afinidade eletiva" entre os dois momentos: a sensibilidade romântica revolucionária (LÖWY, 2002, pp. 21-8). A reflexão de Löwy contida nessa definição possui muitos pontos de semelhança com as de Ernst Bloch, que, reconhecidamente, influenciou-o. Ecoa com destaque a ideia de utopia como caminho para o futuro aberto na retomada do passado, como exposto em Thomas Münzer, teólogo da revolução (1919) ${ }^{6}$.

Essa utopia a que Löwy se refere era constituída do mesmo conteúdo anímico que alimenta os movimentos "materialistas" - aqui, no sentido da ênfase na aplicação dos materiais - mencionados por Dupré em

\footnotetext{
4 Essa relação crítica estabelecida entre os situacionistas e o surrealismo está registrada no conjunto de 11 fólios manuscritos de Guy Debord pertencentes ao fundo Guy Debord da Bibliothèque National de France (FLAHUTEZ, 2013, pp. 46-8).

5 Posteriormente essas ideias seriam pormenorizadas em seu célebre ensaio Teoria da vanguarda, publicado pela primeira vez em 1974 (BÜRGER, 2008).

6 O próprio Bloch definiu essa obra, no epílogo de 1960 à edição alemã, como carregada de um "romantismo revolucionário" que dava continuidade ao iniciado em Espírito da utopia (1918) e que encontraria sua expressão mais acabada em O princípio da esperança, escrito entre 1938 e 1947 e publicado entre 1954 e 1959 (BLOCH, 1968, p. 257). Para uma melhor definição da leitura que Löwy faz da obra de Bloch, veja-se Löwy (2009, pp. 11-28). A respeito dos conceitos de utopia e romantismo nesse mesmo autor, ver Löwy; Sayre (2015) Löwy (2010). Para um detalhamento da relação entre esses conceitos e as vanguardas, conferir Löwy (2011). Mais especificamente sobre o Maio de 68, consultar Löwy (2008).
} 
sua caracterização da década de 1960, a qual é endossada por Raymond Perrot. Segundo Perrot, enquanto alguns empreendiam "uma análise desconstrutiva dos ideologismos apegados seja à cor, seja à matéria, seja ao enquadramento, seja à posição da obra no espaço de exposição", outros, como "Equipo Cronica, os Malassis ou o meu (DDP), prenderam-se à noção de códigos imagéticos". A maior parte desses novos grupos estava ligada ao Salão da J ovem Pintura, que então promovia "as trocas entre o realismo poético francês e a Pop Art, depois a Figuração Narrativa e a figuração engajada" (PERROT, 1996, p. 15). E boa parte deles integraria o Ateliê Popular durante o Maio de 68.

\section{O novo realismo no Salão da J ovem Pintura}

Antes disso, ao menos desde 1936, um "novo realismo" já vinha sendo debatido em Paris entre os combatentes antifascistas, sob coordenadas do Partido Comunista Francês (PCF). Essa tendência se organizou em torno da obra A querela do realismo, defendida pelo poeta Louis Aragon7, e posteriormente assumiu bases francamente zhdanovistas com a União dos Artistas Plásticos (1947-48). Essa vertente, que dominou o realismo francês até 1953, estava agrupada principalmente em torno do Salon des Moins de 30 Ans, criado em 1941 e mantido até 1948 com a preocupação de "reagir contra a arte abstrata". Intuito que foi reforçado por outros salões do período, como o Salon d'Automne e o Salon de Peintres Témoins de Leur Temps. Após o encerramento do "Salão dos com Menos de 30 Anos", foi criado, em 1950, o Salon de la J eune Peinture com o intuito de continuar algumas de suas atividades, especialmente a divulgação de jovens realistas ${ }^{8}$.

Na primeira exposição do Salão da J ovem Pintura, em janeiro de 1950, na Galerie des Beaux-Arts, foram apresentados 120 quadros e, em 1952, ao se mudar para a Galerie de la Boétie, o salão foi celebrado pela crítica como um benéfico retorno de Courbet, como assinalou Aragon em artigo daquele mesmo ano (PARENT; PERROT, 2016, p. 9). Muitos dos artistas ali presentes habitavam o conjunto de Ateliês La Ruche, onde já era desenvolvido um trabalho coletivo com o mesmo objetivo de romper com certo aspecto "saint-sulpicien" do realismo socialista, sem cair no abstracionismo. O grupo gravitava em torno da figura de Paul Rebeyrolle, redator dos estatutos da "Association dite de la J eune Peinture" (junto a

7 La querelle du réalisme foi publicado sob os cuidados de Aragon, sintetizando os debates a respeito do realismo em pintura organizados pela Maison de la Culture em maio de 1936.

8 Para maior detalhamento das posições assumidas pelos artistas vinculados ao PCF ao longo da década de 1940, consulte-se (RANCILLAC, 2000, pp. 173-204; BERTHET, 1990). 
Maître Guillemot, advogado do PCF). Em 1953, Rebeyrolle se tornou membro do PCF9, em que militou até 1956.

Esse alinhamento político fez que a desestalinização por que passava o Partido Comunista contagiasse o Salão do ano seguinte, o qual marcou a troca deliberada do realismo socialista pela retomada da "tradição francesa", iniciando um efêmero período de figuração "apolítica". Tanto a consolidação do Salão quanto os rumos por ele tomados estavam estreitamente ligados ao crescimento de uma nova "civilização do lazer" decorrente do boom econômico do pós-guerra promovido em território francês pelo Plano Marshall e que, no campo das artes plásticas, expressou-se no interesse pela arte abstrata, impactando de diferentes maneiras todas as demais formas de pintura. Desencadeou-se uma repentina subida dos preços das obras, influenciando o perfil do próprio Salão da J ovem Pintura que, com a dita apoliticidade, tornou-se uma plataforma publicitária para a promoção mercantil de novos artistas na passagem da década de 1950 para a seguinte.

Muitas das incursões pelo campo da abstração, verificadas entre seus integrantes no período (especialmente os não comunistas), podem ser lidas mais como uma adequação às demandas do mercado que propriamente como resultado de aspirações estéticas ou políticas. Abstração e realismo passaram a coexistir, sendo que este último tendeu, cada vez mais, a se confundir com um figurativismo banal ("figuração tipo rive-droite"), gerando a predominância, entre os anos de 1959 e 1963, de um "realismo poético", tendência hoje reconhecida como Réalité Poétique. Como resposta a esse encaminhamento, emergiu, ainda em 1962, notadamente pelas mãos de Eduardo Arroyo, uma Nova Figuração que inicialmente foi lida em associação com o pop. Algo repetido no ano seguinte, abrindo então espaço para os comunistas da "segunda geração da Ruche", composta por Francis Biras, Gérard Tisserand, Henri Cueco, J eanClaude Latil, Lucien Fleury, Michel Parré, Walter Spitzer e Péraro (PARENT; PERROT, 2016, p. 25).

Essa equipe, liderada por Cueco, orquestrará um "golpe" na direção do Salão, durante a Assembleia de 1963, com a finalidade de renovar suas posições, deflagrando, no ano seguinte, uma "crise intestina" entre os discípulos de Pierre Bonnard, fechados à realidade contemporânea, e a nova geração, inteiramente devotada a ela e a seus temas, como ideologia, política e sexualidade. Essa mudança no Salão se originou, mais uma vez, menos de uma "crise da forma" que de uma "crise de intensão",

\footnotetext{
9 Pierre Descargues escreveu uma biografia de Rebeyrolle já em 1951. Posteriormente, J ean-Paul Sartre dedicou o texto Coexistences à sua exposição da galeria Maeght (1970), originalmente publicado na revista da própria galeria, Derrière Le Mirroire (Paris, n. 187, octobre 1970) e reproduzido em Situations IX. Michel Foucault escreveu, na mesma revista (n. 202, mars 1973), um artigo sobre o trabalho do artista, intitulado Rebeyrolle.
} 
objetivando trazer o engajamento de volta ao coração do Salão. Tratou-se fundamentalmente de, a partir do pop e contra o pop, transformar em crítica aquilo que nele soava como apologia.

Paralelamente ao salão, uma série de exposições organizadas por iniciativa do crítico e editor Gérard Gassiot-Talabot, como Mythologies Quotidiennes (1964), Figuration Narrative (1966), Bande Dessinée et Figuration Narrative (1967) e Le Monde en Question (1967), consolidava esses avanços da pintura francesa no caminho aberto pelo pop, mas portando uma justaposição narrativa de imagens própria. Essa narratividade havia sido inaugurada pela multi-iconicidade e polissemia discursiva alcançada por André Fougeron em Civilização atlântica (Salon d’Automne, 1953), na qual "as figuras ainda se integram em uma aparência de perspectiva linear e espacial, unificadora” (PERROT, 1996, p. 55). A única diferença - longe de ser pequena - existente entre Fougeron e seus sucessores, como Gilles Aillaud, Arroyo, Antonio Recalcati, Peter Klasen, Bernard Rancillac, Télémaque, Edgard Naccache, Erró, os grupos Cronica, Realidad, Malassis e o DDP, residia na "pasta, o toque, um métier de artista" existente em Fougeron e abandonado pelos que vieram depois.

Diferença notável, assim como aquela estabelecida entre estes últimos depois de 1968 no tocante à "hesitação entre a veemência política ou a simples constatação, segundo a vontade dos artistas e, claro, segundo as recusas e censuras do mercado". Ainda uma terceira distância diz respeito à iniciativa de Fougeron em atribuir significado às diferentes “células representativas” (PERROT, 1996, pp. 118-51). Nesse "herdeiro de Dada e ao mesmo tempo precursor da Pop Art", havia uma complexidade de informação advinda da "Escola de Paris" (sobretudo de Picasso, Braque e Léger), diminuída nos seus sucessores, comprovando a existência de “caminhos de nossa percepção estética que vão e vêm de David, Delacroix, Géricault, Daumier, Courbet, a Rebeyrolle, Arroyo, Erro, Rancillac, os Malassis, DDP... e atualmente Hans Haacke" (PERROT, 1996, p. 167) ${ }^{10}$.

Tentemos entender o propósito e as especificidades dessa distinção. Ao mesmo tempo em que Henri Cueco, Gérard Tisserand, Michel Parré e Lucien Fleury assumiram o comitê diretor da J ovem Pintura, surgiram ali projetos coletivos que visavam à anulação do estilo individual persistente na Figuração Narrativa, já em vias de se politizar. Na verdade, o "golpe" na direção tinha como finalidade viabilizá-los, o que ocorreu primeiramente por iniciativa de Aillaud, Arroyo e Recalcati em Une passion dans le désert (1965). Não era a primeira vez que artistas plásticos trabalhavam em conjunto, muito menos que se justapunham trabalhos de diferentes

10 Sobre a história do tantas vezes referido grupo DDP, formado em 1971 por François Derivery, Michel Dupré e Raymond Perrot, veja-se o catálogo retrospectivo (DERIVERY; DUPRÉ; PERROT, 2005) e o livro (DERIVERY; DUPRÉ; PERROT, 1999). 
artistas em uma única obra, mas "é a primeira vez que uma pintura é definida realmente em comum, executada em comum, cada um podendo modificar tal pedaço realizado pelo outro e reciprocamente, sem que as diferenças de estilo fossem obstáculo à unidade da obra" (PARENT; PERROT, 2016, p. 34).

A inciativa dos "três iê iê iê da pintura", como foram chamados pejorativamente pelo crítico Pierre Cabanne, foi repetida por eles em Vivre et laisser mourrir, ou la fin tragique de Marcel Duchamp, apresentada na exposição La Figuration Narrative dans l'Art Contemporain, organizada por G. G. Talabot no mesmo ano. Uma obra que denunciava "a teoria pseudoduchampiniana que se tornará a referência fundadora da Arte Contemporânea", uma verdadeira "contrarrevolução formalista" (DERIVERY, 2013a, pp. 20-1)11. Nessa mesma edição, elevando a visibilidade do Salão, participaram os já reconhecidos Rancillac e Télémaque, além do Equipo Cronica, que confirmava a prática do trabalho coletivo, a busca de novas resoluções formais e o cuidado com a apresentação textual das obras; iniciativas que foram duramente castigadas pela crítica francesa.

Esse foi o marco de 1965 para a arte francesa, um corte no que diz respeito à autonomia estética do objeto artístico e uma consequente "indiferença total com as questões de estilo" decorrentes dessa anulação. Objetivos tornados mais uma vez transparentes em Homenagem ao verde, gerando novos conflitos que se estenderiam por todo o ano seguinte. $\mathrm{O}$ desentendimento entre alinhados ao PCF e dissidentes, mormente da linha maoísta, ocasionou uma reorganização interna do Salão que, em 1967, impede a participação de artistas que estavam "formando escola", como julgados os casos de Rancillac, Télémaque, J ean-Pierre Raynaud e Valerio Adami. Outros, como Klasen, Guy de Rougemont, Gérard Fromanger e Sergio Birga, foram tecnicamente desclassificados por motivos variados, como "falta de politização", "excesso de politização" etc. ${ }^{12}$.

Isso ocorria ao mesmo tempo em que novos integrantes eram aceitos, como Pierre Buraglio, representante de uma nova abstração que inspirou iniciativas como as dos grupos Support/Surface ${ }^{13}$ e BMPT. Aliás, a passagem meteórica deste último grupo pela edição de 1967 ajuda-nos a

11 Nessa passagem, o autor se refere ao nouveau réalisme, tendência liderada pelo crítico Pierre Restany, a qual se movia no polo oposto à politização proposta pelo Salão da J ovem Pintura, como também registrou Bernard Rancillac: "E Restany, que certamente permanecerá como o instigador mais inventivo do decênio 1960-1970, seria incapaz de insuflar no Nouveau réalisme um sentido político" (RANCILLAC, 2000, pp. 227-8). Essa visão se repete em quase todos os integrantes do Salão que, em algum momento, comentaram a atuação do referido grupo.

12 Daniel Riberzani afirma, em Bernard Rancillac et la figuration narrative, que, "apesar das diferenças de práticas e de conceitos, suas pinturas [de Rancillac e Télémaque] eram consideradas burguesas" (RIBERZANI, 2013, p. 13).

${ }^{13}$ Sobre a produção desse grupo, veja-se (BOUVIER, 2012, pp. 73-6). 
pensar o contexto da época e os debates que o animavam. Para denunciar a persistência do modelo dos salões burgueses do século XIX, apesar das melhores intenções, no funcionamento da Jovem Pintura, o BMPT abandonou o Salão no dia da inauguração. Atitude que influenciou os rumos da organização do Salão, levando-o a uma reformulação que, nos próximos anos, abolirá o júri, o catálogo e até mesmo o uso de cores. De todo modo, uma considerável mudança estava caracterizada: "se antes de 63/64 são as diferenças políticas que são abolidas no mesmo 'Nirvana' artístico, depois de 65/66, serão as diferenças estéticas que se indiferenciarão em um mesmo projeto político" (PARENT; PERROT, 2016, p. 52). É o que comprovam eventos como a exposição Le Monde en Question ou o Mural de Havana (realizado por Rancillac, Arroyo, Erro, Recalcati, Aillaud, Adami, Edmund Alleyn, Bertholo, Piotr Kowalski, Lourdes Castro, J acques Monory e Rebeyrolle).

O Salão havia se tornado um local de encontro de militantes desde a "linha dura” do PCF até maoístas, trotskistas, anarquistas e situacionistas, passando por integrantes da União de Jovens Comunistas MarxistasLeninistas (UJ CML), althusserianos e telquelianos, o que explica como "no ano seguinte, em maio de 68, a maioria da J ovem Pintura se encontra, naturalmente, espontaneamente, no Ateliê Popular de Belas Artes" (PARENT; PERROT, 2016, p. 54). Devido à deflagração da revolta parisiense de 1968, o salão daquele ano, programado para começar em 4 de maio, foi cancelado. Os quadros que comporiam a Sala vermelha para o Vietnã, em que o engajamento político mais uma vez se ancorou no compartilhamento técnico da atividade coletiva, constituem o único registro de sua programação. A Sala foi executada por 24 artistas e radicalizava os procedimentos esboçados pela Homenagem ao verde: uma vez decidido o tema a ser desenvolvido (a luta do povo do Vietnã contra o imperialismo estadunidense) e a cor vermelha como primeiro passo para a unidade do trabalho, sua materialização deveria resultar de um protocolo bastante específico.

Foi preciso formar um tipo de comissão, composta por todos os pintores que tinham decidido participar da sala. Uma vez determinada, por razões de pura comodidade, uma unidade de formato, o trabalho dessa comissão consistiu em criticar a justeza e a legibilidade do conteúdo ideológico de cada quadro. Nenhuma preocupação formal, nenhuma fonte de unidade de estilo jamais sobrecarregou os debates. Não se tratou, em nenhum caso e em nenhum momento, de julgar o projeto proposto em função de seu "valor estético", de sua "qualidade plástica". A guerra do povo é o único laço que une esses quadros. (PARENT; PERROT, 2016, p. 58)

Havia, contudo, um problema não resolvido na proposta da equipe, como assinalou Bernard Rancillac, um dos fundadores da Figuração 
Narrativa. A Figuração Narrativa buscou recuperar "o discurso figurado, só pintando obras acessíveis às massas, [explorando] seu ponto de junção entre o artista e seu público". Rancillac denomina essa nova figuração de "realismo crítico", depois, "realismo dialético", mesmo que esse método tenha sido incapaz de resolver "o problema das formas de expressão capazes de assegurar esteticamente a comunicação de uma mensagem coletiva" (RANCILLAC, 2000, p. 212). A J ovem Pintura estava ligada a esse mesmo objetivo de rejeição ao expressionismo abstrato que invadia a Europa, especialmente no tocante à retomada da figuração em uma linha conjunta à Figuração Narrativa, mas claramente como uma subversão coletivista do pop ${ }^{14}$.

\section{O Ateliê Popular}

O que se radicalizou a partir de 1965 diz respeito, portanto, ao rigor da concepção que passou a se acomodar esteticamente em benefício do "anonimato e do nivelamento da produção", devendo cada artista "renunciar a seu estilo próprio para conseguir uma realização comum viável". Em outras palavras, passou a predominar no Salão a ideia de que "só o esforço coletivo do processo de criação pode desencadear resultados válidos para a coletividade", o que ocasionou o abandono das pesquisas formais em muitos de seus integrantes. A Cooperativa de Malassis emergiu do conflito entre as frações, como coroação desse intento fracassado do Salão, o que se comprova nas palavras de um de seus líderes, Henri Cueco, ao reconhecer posteriormente que "se aquilo tivesse continuado, eu cairia no realismo socialista" (RANCILLAC, 2000, pp. 207-8).

Algo que revemos, de forma ampliada, nas palavras de Gérard Fromanger, quando entrevistado por Hans Ulrich Obrist, em 1996, ao resumir em uma frase o problema enfrentado pelos diferentes grupos surgidos nos anos 1960: "É preciso pintar a revolução ou revolucionar a pintura"? Ele prossegue: "para mim, para pintar a revolução, era já preciso revolucionar a pintura. Se não revolucionássemos a pintura, tombaríamos no realismo socialista ou no realismo capitalista" (FROMANGER, 2016, p. 22). Este último - o "realismo capitalista" - deve ser lido em um registro

${ }^{14}$ Com a finalidade de esclarecer a distinção entre a Figuração Narrativa e a Figuração Crítica, vale recorrer às palavras de François Derivery: "A contestação social e cultural dos anos 1968-1975 não será mais que um parêntese nessa evolução programada até uma arte complacente e de reverência com relação ao poder político e ao mercado. Assim, amputada de sua versão perturbadora - uma Figuração Crítica rapidamente marginalizada - , a Figuração Narrativa introduz a Pop Art e sua ideologia na pintura europeia" (DERIVERY, 2013a, p. 18). Veja-se também seu artigo (DERIVERY, 2013b, pp. 31-9), assim como o bem mais completo estudo de Raymond Perrot (2005), que serve de base para as análises de Derivery e ao qual este último dedicou uma crônica no segundo número da revista éCRItique (DERIVERY, 2005, pp. 153-7). 
mais amplo que o da figuração, abarcando toda a gama de pintura "de constatação", como também definiu Maurice Matieu ao afirmar, na mesma época, que "do mesmo modo que há um realismo socialista há um realismo capitalista que se chama o Conceitual" (DERIVERY; MATIEU, 2000, p. 18).

Os desdobramentos desse empenho coletivista seriam mais bem notados no Ateliê Popular, que, seguindo as mesmas diretrizes nãoautorais, produziu entre 13 de maio e 27 de junho grandes tiragens de cartazes que, apesar de sua consciência do contexto e da intencionalidade concreta que os determinava, foram imediatamente "recuperados" pelo mercado de arte, como destacou Raymonde Moulin em seu artigo Vivre sans vendre (CASSOU, 1968). Muitos dos cartazes produzidos no Ateliê foram apropriados por colecionadores e depois expostos ou comercializados dentro do circuito oficial de arte, fazendo aparecer a tematização da "recuperação" já em janeiro de 1969 no editorial escrito por Aillaud ao V Boletim da J ovem Pintura. Um esforço artístico e teórico que Pierre Gaudibert considera, em seu artigo Contestation, récupération et modernité (Opus n. 15, dez. 1969), um deliberado afastamento crítico com relação ao realismo socialista ${ }^{15}$.

Após os eventos de 1968, com o sentimento dúbio de traição por parte do PCF e da Confédération Générale du Travail (CGT) - que optaram pela via eleitoral - e, ao mesmo tempo, de que nada poderia voltar a ser como antes, deu-se mais uma radicalização à extrema-esquerda no Salão da J ovem Pintura, desdobrando-se na formação de novos coletivos sob a bem conhecida consigna "a luta continua”. O lançamento do segundo boletim informativo do Salão, em dezembro de 1968, registrou essa transformação, que incluía a interdição da publicação de seus catálogos, mantida até 1972. O Boletim da Jovem Pintura se tornava "uma experiência única na história dos Salões e mesmo na história das relações do pensamento e da prática pictural" (PARENT; PERROT, 2016, p. 70) devido à politização, coletivização das discussões e anonimato dos textos.

Você sonha com uma vida de pintor de sonhos e eu, pintor, vivi meu sonho no Maio de 68: eu falei tanto, escutei, agi que eu esqueci de pintar durante dois meses. A maioria dos artistas vivenciou o mesmo fenômeno, mas eles não mexeram mais nos seus pinceis durante os dois ou três anos seguintes. (FROMANGER, 2016, p. 14)

\footnotetext{
${ }^{15}$ Quanto ao afastamento do grupo com relação às ideias zdanovistas, veja-se os Bulletins de la J eune Peinture n. 3, 4 e 5, em que há uma aproximação das ideias de Brecht. Para um apanhado geral da produção do Ateliê, uma pequena brochura publicada pela Usines, Universités, Union (UUU), Atelier Populaire présenté par lui-même, registra tais atividades reproduzindo 87 de seus cartazes. Posteriormente, com apoio do editor londrino Dobson, foi lançado o ainda mais completo Mai 68 début d'une lutte prolongée, com textos da edição da UUU traduzidos para o inglês e 197 reproduções, sendo 86 em grande formato e em cores.
} 
Essas palavras de Fromanger atestam como a organização do Salão passou a ser guiada por uma "harmonia conflitiva" entre as inclinações mais para a pintura nos antigos membros e o intelectualismo militanteintervencionista da nova geração, que ganhava força com a esquerda pós68, especialmente entre anarquistas e maoístas. Com a expectativa criada em torno da XX edição (janeiro de 1969) devido à Sala do Vietnã e ao Ateliê Popular, a opção dos novos pintores foi pela política. Uma politização da arte que teve como consequência o descentramento da exposição, colocada em pé de igualdade com o programa de grupo e os boletins que o vinculavam. Uma vez que não havia mais a centralidade da exposição, os boletins assumiram um papel teórico-informativo que tornou a forma-catálogo obsoleta, gerando "uma associação que parece doravante mais um Partido (mesmo se ele é relativamente heterogêneo com suas tendências internas somadas) que um salão 'ordinário'”' (PARENT; PERROT, 2016, p. 79).

Sua contraprova é o boletim n. 4, de maio de 1969, anunciando o primeiro salão da história a assumir uma luta ideológica cuja arma principal é "o marxismo". Era declarada guerra aos artistas "cães de guarda" que aceitam circular pelo sistema artístico burguês e exibir, por meio de suas obras, "a imagem da liberdade total e do poder criador ilimitado do espírito humano. É nesse sentido que ele [o artista] é um defensor particularmente eficaz do sistema de exploração capitalista" (PARENT; PERROT, 2016, pp. 80-1). Estes protestos contra a produção de um "retorno à ordem", anunciado pela eleição de Pompidou, ainda transpareceram em outras modalidades de agitação e boicotes a eventos, como a Bienal de São Paulo (1969), a exposição de Yves Klein no Museu de Artes Decorativas de Paris (março de 1969) e a VI Bienal de Paris (outubro). Ou ainda na I Bienal Internacional Arte e Revolução ("contrabienal"), organizada no Grande Hall, alguns pavilhões ejardins da Cité Universitaire. Na década seguinte, esse caminho seria fortalecido pela aliança com pintores não-europeus exiliados em Paris. Primeiro com a organização da exposição América Latina Não Oficial, na Cité Internationale, e depois com a fundação do Grupo Denúncia ${ }^{16}$, do Museu da Solidariedade Salvador Allende, do Museu da Solidariedade com o Povo da Nicarágua, da Exposição Internacional pela Palestina e do Museu Contra o Apartheid.

${ }^{16}$ Fundado em 1972 por J ulio Le Parc, Gontran Guanaes Netto, J osé Gamarra e Alejandro Marcos. 


\section{0 retorno à ordem}

A tentativa de dar continuidade a esse enfrentamento ideológicocultural exigiu uma politização progressiva da pintura - algo já sinalizado pela radicalização coletivista da Nouvelle Figuration, em meados dos anos 1960, no Salão da Jovem Pintura e no Ateliê Popular - , originando a aparição, nos anos seguintes, de novos grupos, como a Cooperativa de Malassis (1970-81), o Fronte dos Artistas Plásticos (1971-77), o Coletivo Antifascista (1974-77) e inúmeros outros subgrupos, como Groupe DDP (1971-98), Grupo Denúncia (1972-) e Peintres du 18e (1974). Esse foi o motivo de Perry Anderson ter considerado o maio-junho de 1968 uma "verdadeira quebra na história política e intelectual na França do pósg3uerra". Uma extraordinária relevância que, não por acaso, tornou-se o mote principal da resposta/autodefesa de Pierre Nora às ideias de Anderson ${ }^{17}$.

\section{Considerações finais}

Partindo do panorama esboçado e buscando identificar um sentido comum ao conjunto de práticas artísticas descritas, observamos que coexistiram divergências e enfrentamentos internos ao longo de praticamente todo o itinerário da Jovem Pintura. Por mais que a politização da atividade artística seja quase sempre o denominador comum, são inegáveis os diferentes modos como ela foi concebida, assim como a longevidade de suas consequências para cada um dos envolvidos. A resistência ao anonimato autoral, associada à necessidade de afirmação do estilo individual foi, como vimos, o ponto crítico dessas divergências. Não se tratou apenas de relutância em aceitar a anonimização estilística, pois, mesmo quando o estilo individual não foi colocado em questão, alguns artistas jamais aceitaram a interdição da assinatura, questão que foi muito bem tematizada por Françoise Docquiert ao confrontar o anonimato autoral com as aspirações profissionais que permeiam o campo artístico: "imperceptivelmente, mas radicalmente, a assinatura introduz a obra num mundo diferente do objeto" (DOCQUIERT, 1977, p. 160).

\footnotetext{
${ }^{17}$ A discussão segue a seguinte cronologia: Perry Anderson publicou Dégringolade na London Review of Books, v. 26, n, 17, em 2 de setembro de 2004, disponível em <http://www.lrb.co.uk/v26/n17/ perry-anderson/degringolade> e Union Sucrée na London Review of Books, v. 26, n. 17, em 23 de setembro de 2004, disponível em <http://www.lrb.co.uk/v26/n18/ perry-anderson/union-sucree>. Os dois artigos foram reunidos, traduzidos para o francês e publicados com o título de La pensée tiède: un regard critique sur la culture française, em abril de 2005, pela editora Seuil, trazendo como acréscimo o texto resposta de Nora, intitulado La pensée réchauffée (ANDERSON, 2005).
} 
Ao que tudo indica, o empenho constante em romper com o "mito da arte" - subentendido, no mundo burguês, em sua sacralidade, intemporalidade e transcendência - não diminuiu as dificuldades em se romper com outros valores relativos à concepção burguesa do sistema artístico. Isso se verifica tanto no Salão da J ovem Pintura quanto no Ateliê Popular, demonstrando como permaneceu uma vontade de manutenção da institucionalidade atingida pelo artista no mundo burguês, a despeito das modificações na concepção da obra. Isso significa, nas palavras de François Derivery, reconhecer que a anulação do indivíduo "não é nada compatível com uma perspectiva de carreira" (DERIVERY; MATIEU, 2000, p. 13). O que nos cumpre observar, por fim, é como o projeto comum de luta por um espaço social de crítica e denúncia à opressão empurrou esses artistas para uma situação inteiramente nova, que implicava uma reformulação, ainda que inopinada, da função social da obra de arte como ritual coletivo.

Foi essa concepção ou entendimento que permitiu aos diferentes envolvidos não apenas se reconhecerem como participantes de uma mesma empreitada, mas como herdeiros e continuadores de uma tradição coletivista recalcada por determinados valores contidos na arte burguesa: “o projeto moderno em seu início era o contrário de um projeto centrado sobre o indivíduo. A autonomização deste - e, logo, do artista reivindicada pelo Iluminismo não implicava em nada o esquecimento do outro e do interesse coletivo" (DERIVERY, 2013a, p. 54). Eis a linha estabelecida pelo "individualismo democrático" que nos permite reconhecê-los como continuadores de uma linhagem que vem dos impressionistas - que, "em sua luta contra o academismo, desconstituíram o público, inaugurando a ideia de aventura intelectual ou de vanguarda" (DERIVERY; MATIEU, 2000, p. 14) - , passa pelas vanguardas históricas do início do século e pelo situacionismo. Essa consciência de continuidade foi definitiva para o reconhecimento do peso social das instituições sobre a produção individual, fazendo que, entre os artistas que analisamos, a consciência dessa disputa ocupasse uma posição central, influenciando todas as questões relativas à forma, ao conteúdo, ao estilo ou à técnica em arte.

Empregando diversas estratégias contra a ordem dominante do visível que satura o olho por meio de representações estéticas e ideológicas de objetos, a pintura é revolta por seu próprio movimento, no aqui e agora. (...) Definitivamente, os pintores podem desempenhar o papel de analistas das instituições sociais que os marginalizam. Seus quadros manifestam a verdade latente do sistema institucional. (DOCQUIERT, 1977, p. 236) 
Esse verdadeiro alerta a respeito da "ideologia da Criação", da liberdade incondicionada do gesto individual que reivindica para usos artísticos “o conceito religioso de criação ex-nihilo" (DERIVERY, 2013a, p. 101), certamente foi o ponto de união entre os muitos nomes mencionados nas páginas anteriores, apesar das igualmente numerosas diferenças que destacamos. Uma ideia que se manifestou, acima de tudo, pelo enfrentamento e denúncia da "arte contemporânea", considerada uma recuperação deturpada e instrumentalizadora do projeto modernista das vanguardas históricas que, a partir de então, foram convertidas em uma espécie de vanguarda de salão. Para os artistas de que falamos, a arte contemporânea à qual eles se opunham não era uma atualização da modernidade, pois esta última presumia uma autonomia individual e social com relação ao mercado. Sua grande diferença reside, portanto, no fato de que essa arte internacional oficial já não acompanha mais os objetivos originários da arte moderna, muito menos aqueles adquiridos durante os "primeiros 30 anos do século XX", quando a arte finalmente "se abre para a responsabilidade social" (DERIVERY, 2013a, p. 93).

\section{Referências bibliográficas}

ANDERSON, Perry. La pensée tiède: un regard critique sur la culture française. Trad. William Olivier Desmond. Paris: Seuil, 2005.

BERTHET, Dominique. Le PCF, la culture et l'art, 1947-1954. Paris: La Table Ronde, 1990.

BLOCH, Ernst. Thomas Münzer, teólogo de la revolución. Trad. Jorge Deike Robles. Madri: Editorial Ciencia Nueva, 1968.

BOUVIER, Pierre. Une aporie: Support/Surface. éCRItique, Paris, n. 14, pp. 73-6, 1er semestre 2012.

BÜRGER, Peter. “O surrealismo francês”. Trad. J osé Pedro Antunes. In: ANTUNES, J osé Pedro. Tradução comentada de O surrealismo francês de Peter Bürger. Tese (Doutorado) defendida na Universidade Estadual de Campinas (IEL-Unicamp), Campinas, 2001.

. Teoria da vanguarda. Trad. José Pedro Antunes. São Paulo: Cosac Naify, 2008.

CASSOU, Jean et. al. Art et contestation. Belgique/France: La Connaissance/ Weber, 1968.

CHAMBARLHAC, Vincent; LAVIN, Amélie; TILLIER, Bertrand. Les Malassis. Une coopérative de peintre toxiques (1968-1981). Montreuil: L'Échappée, 2014.

DERIVERY, François; DUPRE, Michel; PERROT, Raymond. Le groupe DDP 1971-1998: pratiques collectives, pratiques artistiques. Paris: EC Éditions, 1999. 
Éditions, 2005.

. La peinture collective du groupe DDP. Saint-Estève: EC

DERIVERY, François; MATIEU, Maurice. Deux entretiens. Paris: EC Éditions, 2000.

DERIVERY, François. Art et travail collectif suivi de La politique d’art officiel en France. Paris: EC Éditions, 2001a.

. L'Exposition 72-72. Paris: EC Éditions, $2001 \mathrm{~b}$.

. Le système de l'Art. Paris: EC Éditions, 2004.

. Chronique. éCRItique, Paris, n. 2, pp. 153-7, 1ème semestre 2005.

. L'art contemporain produit et acteur du néoliberalisme.

Campagnan: EC Éditions, 2013a.

. Figuration narrative et figuration critique. éCRItique, Paris, n.

16, pp. 31-9, 2ème semestre 2013b.

DOCQUIERT, Françoise. La peinture politique contemporaine en France.

Paris: Nanterre X, 1977.

DUPRÉ, Michel. Art. Campagnan: EC Éditions, 2015.

FLAHUTEZ, Fabrice. "L'héritage surréaliste: la lecture de Breton". In: GUY, Emmanuel; LE BRAS, Laurence (Dir.). Guy Debord: un art de la guerre. Paris: Bibliothèque National de France/ Gallimard, 2013, pp. 46-8.

FOSTER, Hal. Recodings: art, spectacle, cultural politics. Seattle: Bay Press, 1985.

FROMANGER, Gérard. Gérard Fromanger. Lyon: Fage Éditions, 2016.

GUILBAUT, Serge. Comment New York vola l'idée d'art moderne: expressionisme abstrait, liberté et guerre froide. 3. ed. Nîmes: Éditions J acqueline Chambon, 1996.

LÖWY, Michael; SAYRE, Robert. Revolta e melancolia: o romantismo na contracorrente da modernidade. Trad. Nair Fonseca. São Paulo: Boitempo, 2015.

LÖWY, Michael. A estrela da manhã: surrealismo e marxismo. Trad. Eliana Aguiar. Rio de J aneiro: Civilização Brasileira, 2002.

. Le romantisme révolutionnaire du Mai 68. Revue Contretemps, n. 22, mai 2008. Disponível em: <http://www.preavis.org/ brechenumerique/ article690.html > acessado em 20 out. 2016.

. Ernst Bloch e Theodor Adorno: luzes do romantismo. Trad. Leandro Galastri. Cadernos Cemarx, n. 6, pp. 11-28, 2009. Disponível em: $<$ https:// www.ifch.unicamp.br/ ojs/index.php/cemarx/article/ viewFile/ 10 84/ 794>, acessado em 20 out. 2016.

. Juifs hétérodoxes: romantisme, messianisme, utopie. Paris: Éditions del’Éclat, 2010.

- Carga explosiva: o surrealismo como movimento romântico revolucionário. Trad. Rodrigo Czajka. Temáticas, Campinas, n. 37-38, pp. 11-24, jan.-dez. 2011. 
NICOLE, Racine. "La querelle du réalisme" (1935-1936). Sociétés \& Représentations, n. 15, pp. 113-31, 1/2003.

PARENT, Francis; PERROT, Raymond. Le Salon de la Jeune Peinture: une histoire 1950-1983. Réedition augmentée d'une annexe. Arcueil: Éditions Patou, 2016.

PERROT, Raymond. Esthétique de Fougeron. Campagnan: EC Éditions, 1996.

. De la tache à la figure: la Guerre d'Algérie et les artistes 19541962. Campagnan: ECÉditions, 2002.

. De la narrativité en peinture: essai sur la Figuration Narrative et sur la figuration en général. Paris: Éditions Harmattan, 2005.

RANCILLAC, Bernard. Le regard idéologique. Paris: Éditions Somogy et Guéna, 2000.

RIBERZANI, Daniel. Bernard Rancillac et la figuration narrative. éCRItique, Paris, n. 16, pp. 13-22, 2 ${ }^{\text {er }}$ semestre 2013.

Como citar:

SOUZA, Leandro Cândido de. Aspectos da pintura política na França: de Civilização atlântica ao Ateliê Popular (1953-68). Verinotio - Revista online de Filosofia e Ciências Humanas, Rio das Ostras, v. 24, n. 2, pp. 192209, nov. 2018.

Data de envio: $21 \mathrm{fev} .2018$

Data de aceite: 23 abr. 2018 